\title{
PENERAPAN MULTIMEDIA DALAM PEMBELAJARAN DI TK ANANDA BAGAN BATU
}

\author{
Volvo Sihombing \\ Dosen AMIK Labuhanbatu \\ Jl. Aek Tapa Rantauparapat, Sumut \\ volvolumbantoruan@gmail.com
}

\begin{abstract}
Abstrak - Minat baca anak secara konvensional saat ini kurang begitu menarik seusia anak taman kanak-kanak(tk) sehingga dirasakan alat bantu teknologi secara visualisasi dan gerak sehingga anak lebih tertarik dan mudah dalam proses pembelajaran. Dibangunya aplikasi multimedia sebagai sarana alat bantu membantu anak lebih kreatif dan tertarik untuk belajar serta dapat memacu daya pikir anak-anak dalam bidang pendidikan yang diajarkan disekolah taman anakanak. Bahasa pemrograman yang digunakan adalah bahasa pemrograman VB dan didukung dengan photoshop dalam desain gambar yang ada diaplikasi serta sound recorder untuk merekam suara yang dibangun dalam aplikasi.
\end{abstract}

Kata kunci : multimedia, vb, tk

Abstract - Conventional children's interest in reading is currently not very attractive as a kindergarten age (tk) so that it is felt that visual aids and motion technology aids so that children are more interested and easier in the learning process. The development of multimedia applications as a tool to help children be more creative and interested in learning and can stimulate children's thinking in the field of education that is taught in children's parks. The programming language used is the VB programming language and is supported with photoshop in the design of the existing images applied as well as a sound recorder to record sounds built in the application.

Keywords: multimedia, $v b, t k$

\section{PENDAHULUAN}

Dengan berkembangnya zaman, maka kebutuhan informasi pun semakin banyak. Hal ini juga yang menyebabkan munculnya kemajuan pada perangkat lunak dan diimbangi pula dengan kemajuan dan kecanggihan teknologi beserta perangkat kerasnya. Secara langsung ataupun tidak, teknologi informasi telah menjadi bagian penting dari berbagai bidang kehidupan. Karena banyak kemudahan yang ditawarkan, teknologi informasi hampir tidak dapat dilepaskan dari berbagai aspek kehidupan manusia terutama dalam bidang pendidikan. Sekolah TK Ananda Bagan batu berdiri sejak tahun 2007 dibawah Yayasan Pendidikan Ananda. Paket Aplikasi ini dirasa sangat cocok untuk dikonsumsi anak-anak, terutama bagi para siswa yang duduk dibangku Taman Kanak-kanak (TK). Sebab dalam aplikasi ini didasarkan pada tingkat kemampuan anak dalam memahami materi yang diajarkan dikelas. Bentuk-bentuk pemanfaatan model-model multimedia interaktif berbasis komputer dalam pembelajaran dapat berupa drill, tutorial, simulation dan game.[1]

Aplikasi yang dibangun berisi materi yang disajikan dalam bentuk sederhana, sesuai dengan kemampuan anak-anak, misalnya pengenalan angka, huruf, hewan, transportasi, anggota tubuh, warna, angka dan teka-teki yang dilengkapi dengan gambar-gambar. Hal inilah yang sangat mungkin disukai anak-anak TK. Diharapkan dengan dibuatnya software aplikasi "Penerapan Multimedia Dalam Pembelajaran di TK Ananda Bagan Batu" minat anak-anak untuk belajar sehari-hari yang kurang suka, akan menjadi tertarik dan lebih kreatif serta membantu para guru yang mengajarkan materi. Multimedia merupakan proses penyampaian dengan menggunakan banyak media serta mengkombinasikan tiga elemen seperti teks, gambar dan suara dalam suatu produk bertingkat berbasis komputer sehingga dapat menciptakan presentasi yang dinamis dan interaktif [2]. 


\section{METODE PENELITIAN}

A. Lokasi dan Alat Penelitian

1. Lokasi Penelitian ini dilakukan di TK Ananda dengan alamat J1. Lintas Bagan Batu Km 1 Bagan Batu.

2. Alat Penelitian Sumber daya yang digunakan dalam melakukan penelitian.

3. Hardware 1 unit komputer (PC / Personal Computer), dengan spesifikasi, Intel(R) Core i5, $2.53 \mathrm{GHz}$, Hard disk SATA 500 GB, Memori 2 GB DDR2.

4. Software sistem operasi windows, Visual Basic, Photoshop dan Sound Recorder.

B. Wawancara

Mengambil data dengan mengajukan beberapa pertanyaan yang berhubungan dengan cara pelafalan bahasa indonesia secara baik dan benar baik secara lisan maupun, memberikan bentuk gambar buah, alat transportasi, gambar hewan dan lain -lain.

C. Observasi

Yaitu metode pengumpulan data dengan melakukan pengamatan secara langsung tentang hal-hal yang berkaitan dengan pembelajaran bahasa Indonesia. Untuk mencapai keinginan yang dimaksud maka perlu dilakukan perancangan sistem [3]:

1. Merancang Konsep Merancang konsep merupakan tahap penentu secara keseluruhan dalam pembuatan sebuah aplikasi multimedia agar dalam merancang konsep program aplikasi multimedia yang akan dibangun ini mempunyai tujuan yang jelas dalam menyampaikan informasi.

2. Merancang isi digunakan agar perancangan isi program aplikasi multimedia yang akan dibangun mengandung isi informasi yang sesuai dan beraturan setiap level program dan harus mengacu pada struktur program yang telah ditetapkan pada perancangan naskah.

3. Merancang naskah merupakan langkah awal untuk menyusun dialog yang interaktif secara rinci dan sesuai dari urutan - urutan informasi program yang akan disampaikan kepada pengguna informasi (User).

4. Perancangan grafis digunakan untuk memilih perangkat lunak atau software aplikasi multimedia yang tepat untuk medisain grafis guna mendukung dialog serta setiap tampilan menu program kepada pengguna (User) saat berinteraksi dengan program aplikasi. Selain itu kriteria yang paling penting harus diperhatikan agar hasil program yang akan disajikan mempunyai sifat ramah (User Friendly) kepada pemakai (User).

\section{HASIL DAN PEMBAHASAN}

Untuk mendapatkan predikat "ramah dengan pengguna" maka antar muka berbasis grafis tersebut harus mempunyai tampilan yang bagus, menarik, mudah dipelajari dan mudah dioperasikan oleh pengguna [3]. Aplikasi ini juga didukung dengan animasi dan desain yang dibangun.

Animasi adalah gambar begerak berbentuk dari sekumpulan objek (gambar) yang disusun secara beraturan mengikuti alur pergerakan yang telah ditentukan pada setiap pertambahan hitungan waktu yang terjadi[4]. Adobe Photoshop, atau biasa disebut Photoshop, adalah perangkat lunak editor citra buatan Adobe Systems yang dikhususkan untuk pengeditan foto/gambar dan pembuatan efek [5].

Algoritma yang di gunakan dalam program Visualisasi Pengenalan Huruf adalah sebagai berikut.

1. Start

2. Form Pembuka

3. Menu Utama

4. Pilihan Menu

5. Jika di pilih Pengenalan Huruf Maka di kerjakan No 6

6. Pilihan Menu.

7. Tentukan Nilai Variabel

8. Tampilkan Pada layar.

9. End 


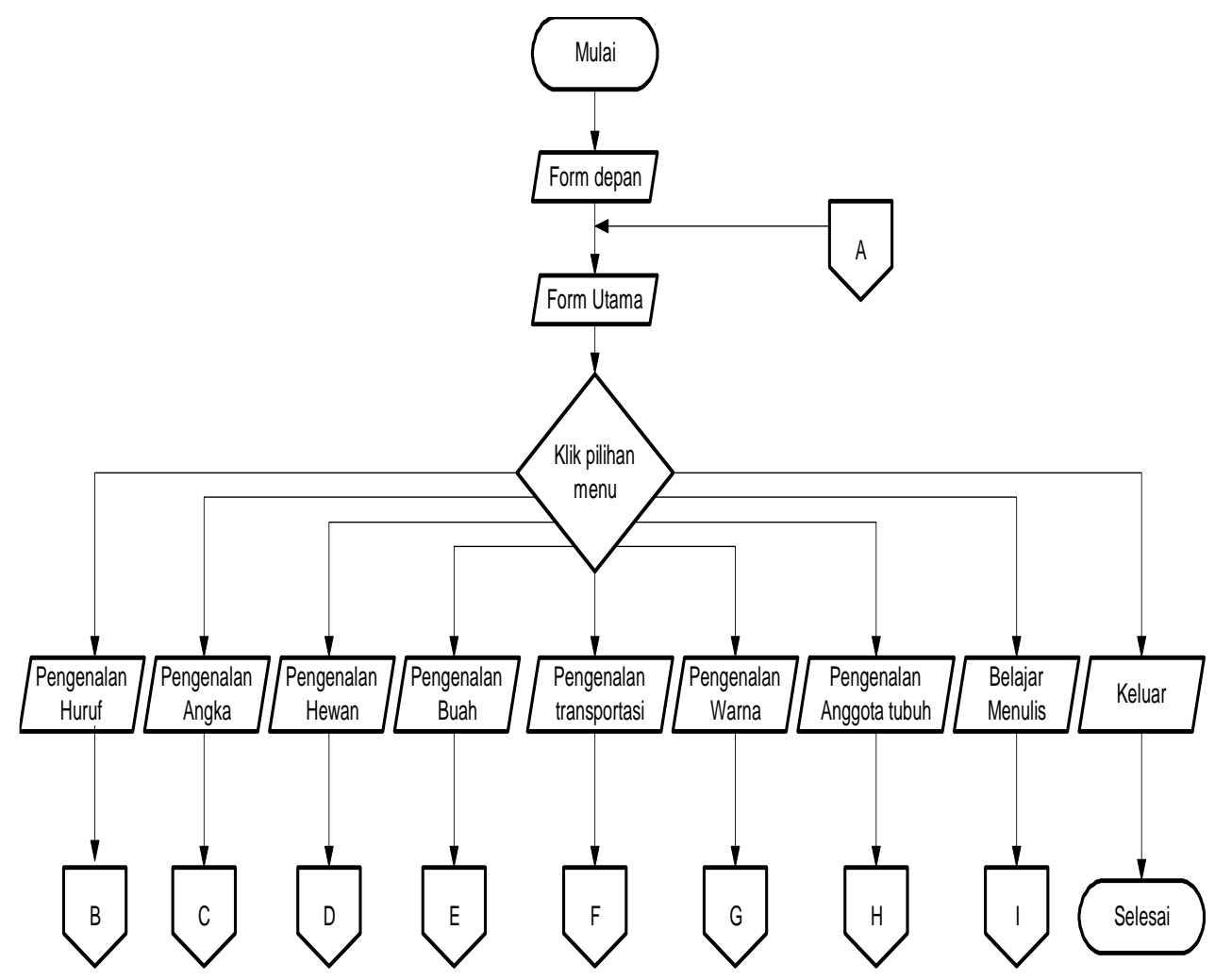

Gambar 1. Flowchart Menu Utama

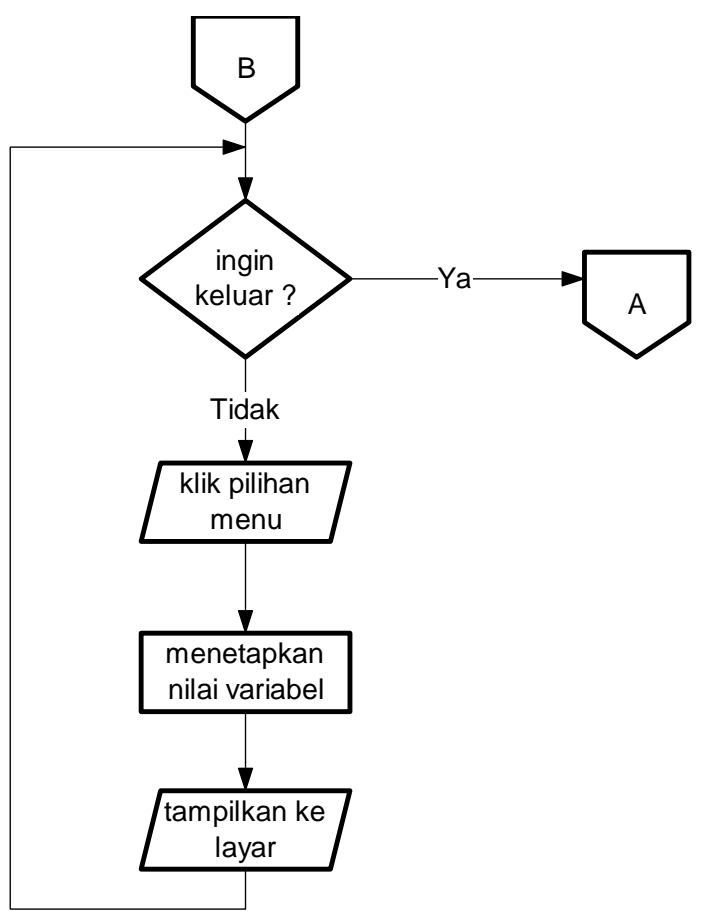

Gambar 2. Flowchart Menu Pilihan Huruf 
Pada Tampilan Flow Menu Pengenalan pilihan Menu Angka, Hewan, Buah - buahan, Transportasi, Warna dan Anggota Tubuh sama dengan Flow dari Pengenalan Huruf.

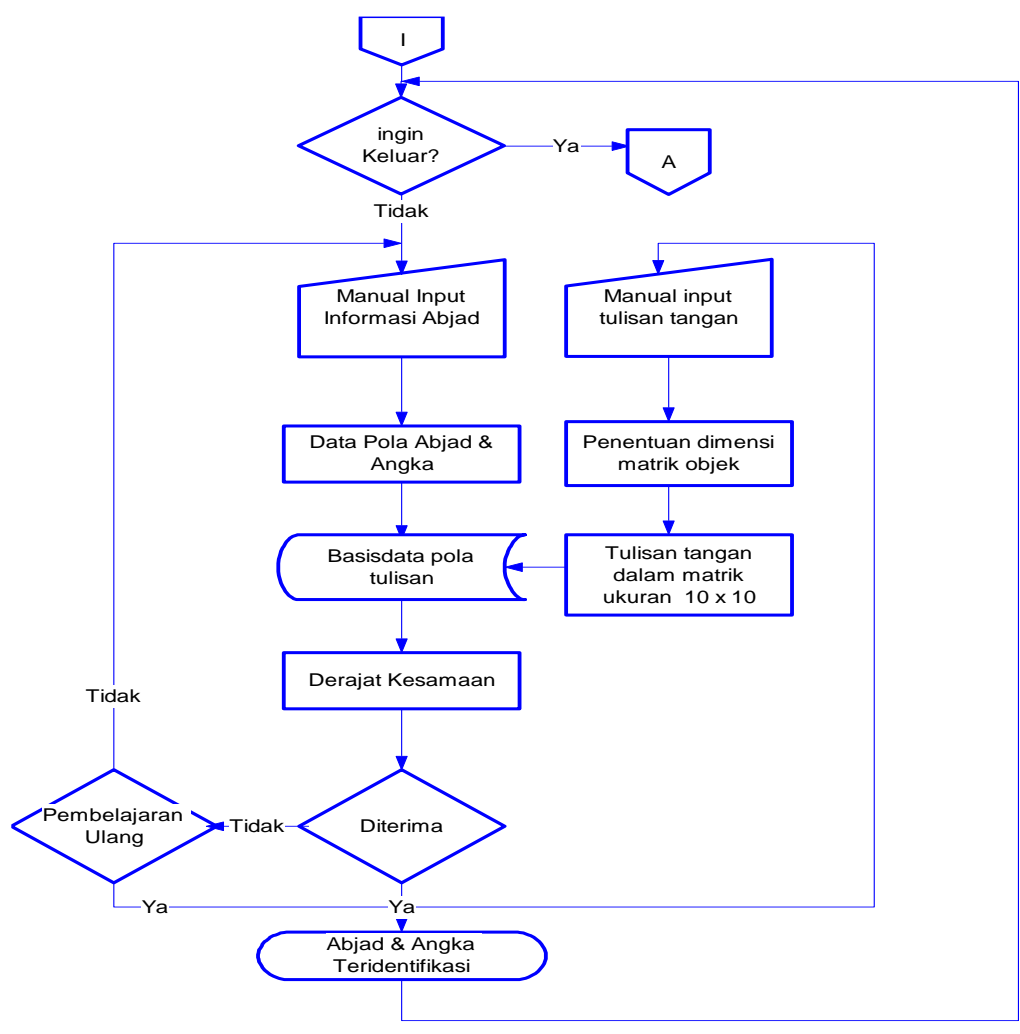

Gambar 3. Flow Menu Pilihan Belajar Menulis

1. Tampilan utama

Tampilan utama ini merupakan tampilan ketika aplikasi dirun, kemudian pilih menu Masuk untuk masuk keaplikasi utama.

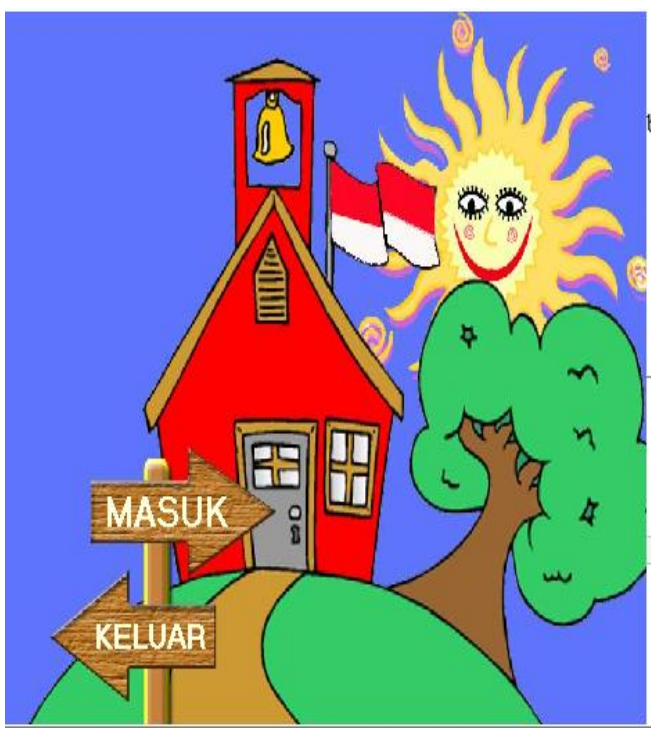

Gambar 4. Menu Utama 
2. Tampilan Antar Muka Program Utama

Tampilan ini merupakan tamplan yang berisi menu-menu yang akan diajarkan didalam kelas seperti tampilan berikut :

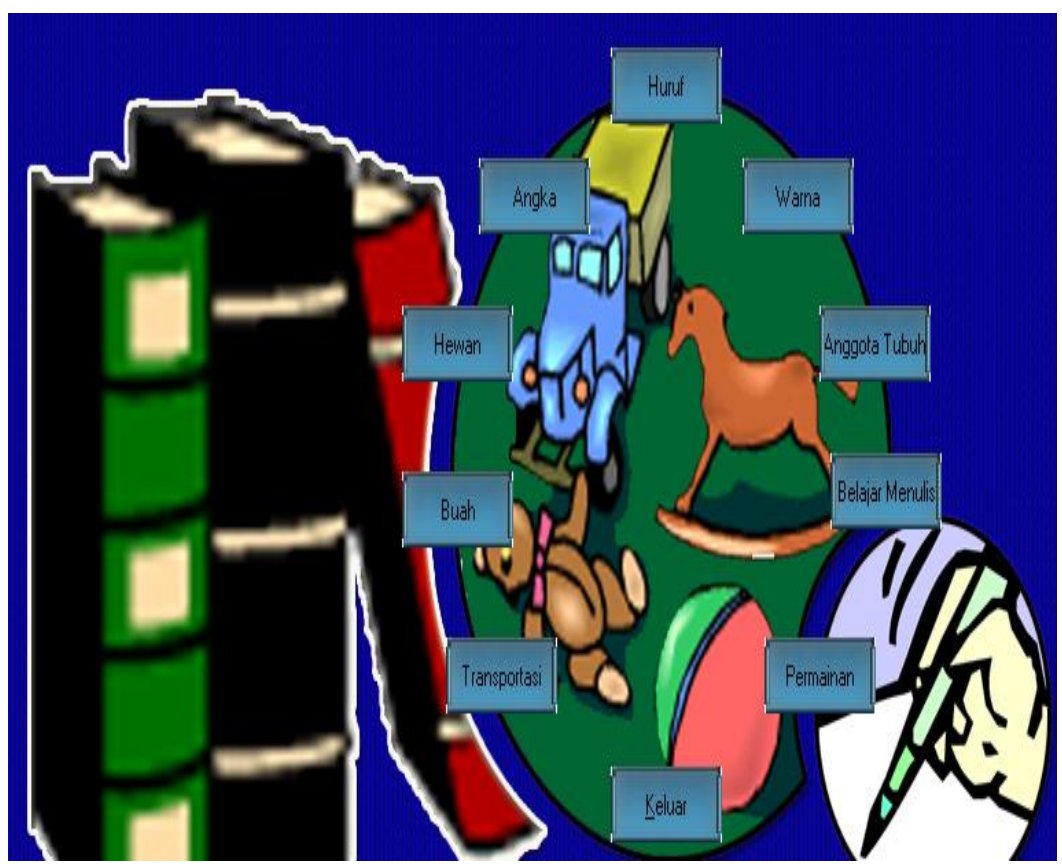

Gambar 5. Menu Utama Antar Program

3. Tampilan Form Huruf

Tampilan form huruf ini merupakan menu untuk mengenal huruf ketika di klik salah satu huruf maka ada suara sesuai huruf yang diklik.

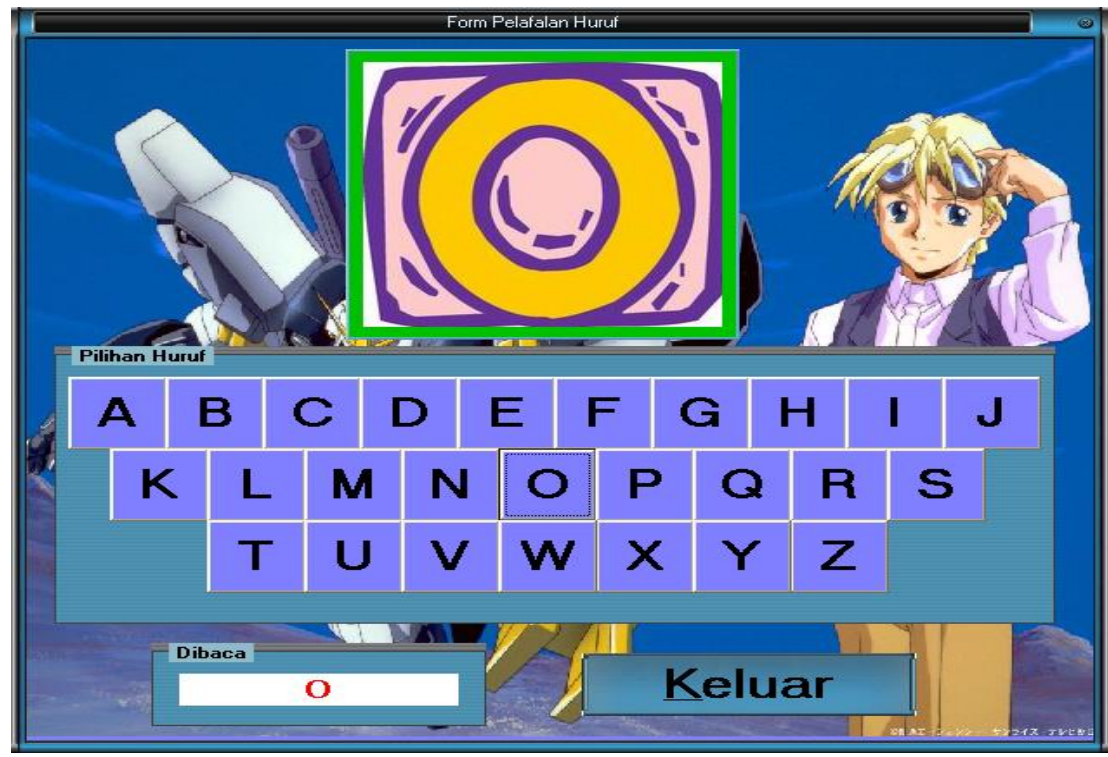

Gambar 6. Form Huruf 
4. Tampilan Form Angka

Menu ini merupakan menu angka yang akan diajarkan didalam kelas untuk pengenalan angka.

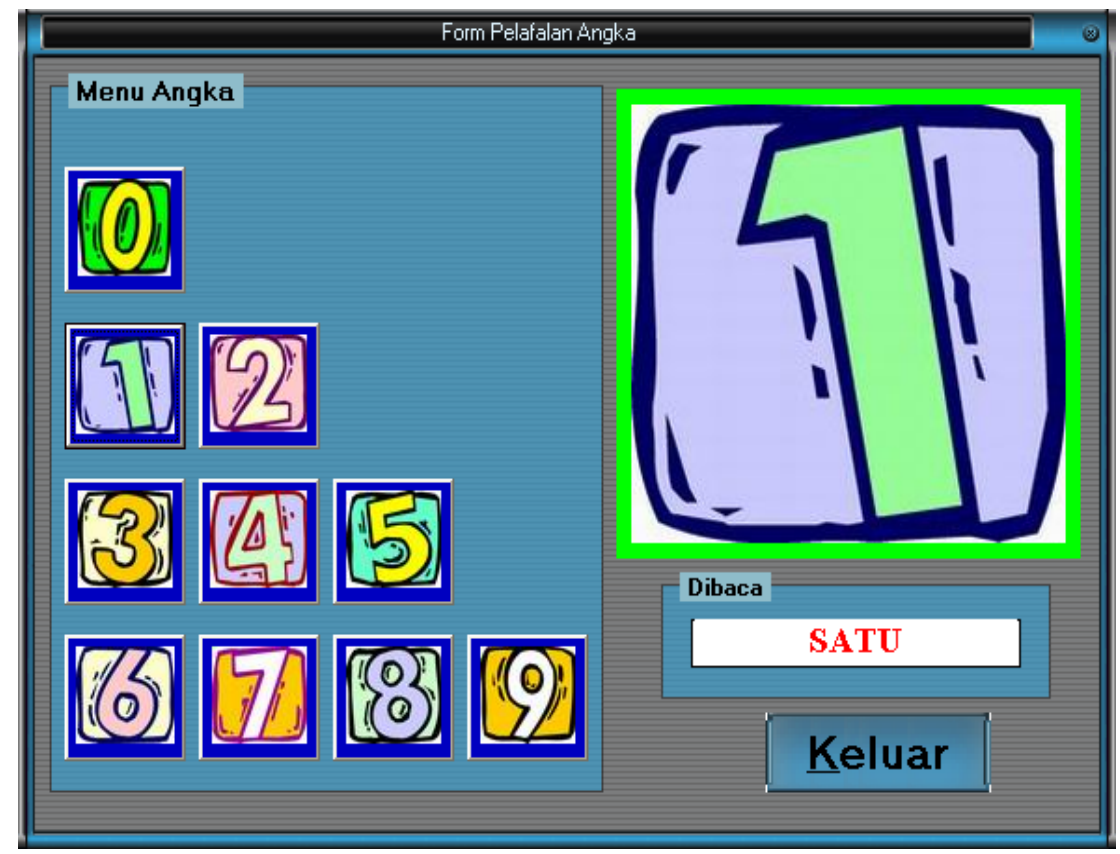

Gambar 7. Form Angka

5. Tampilan Warna

Tampilan warna merupakan tampilan menu warna untuk pengenalan warna

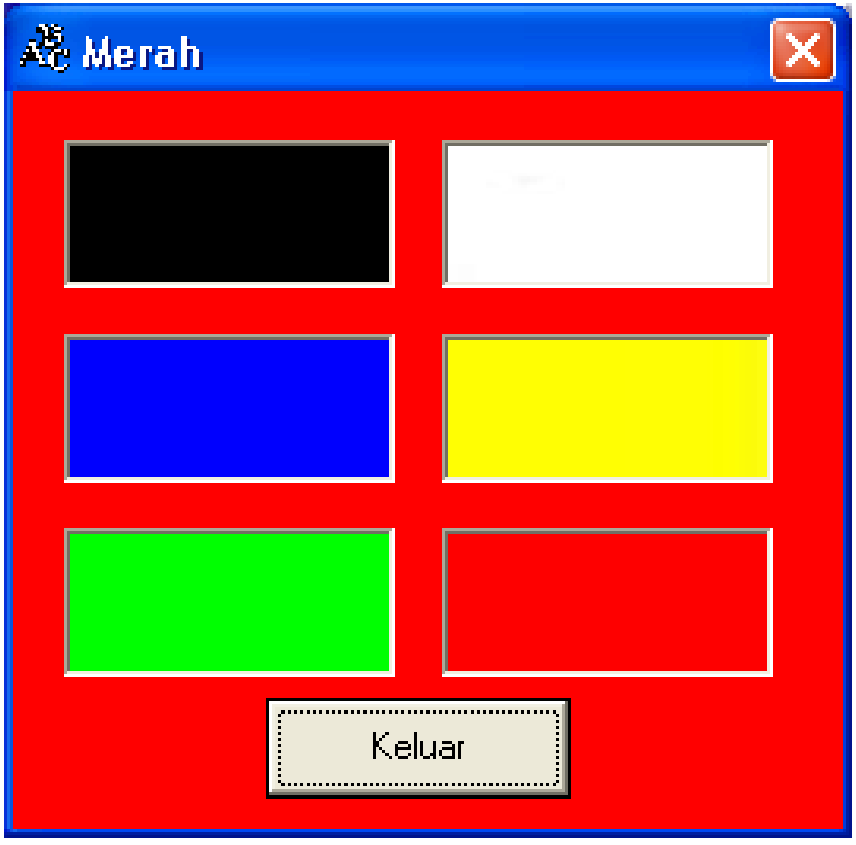

Gambar 8. Form Warna 
6. Tampilan Form Hewan

Tampilan form hewan menu untuk memperknalkan hewan.

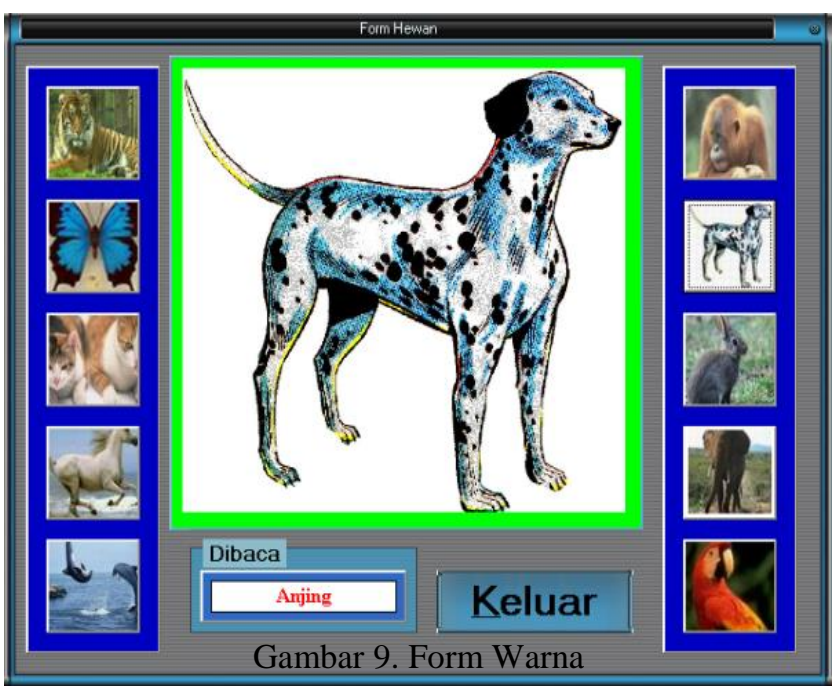

7. Tampilan Anggota Tubuh

Tampilan anggota tubuh untuk memperkenalkan anggota tubuh.

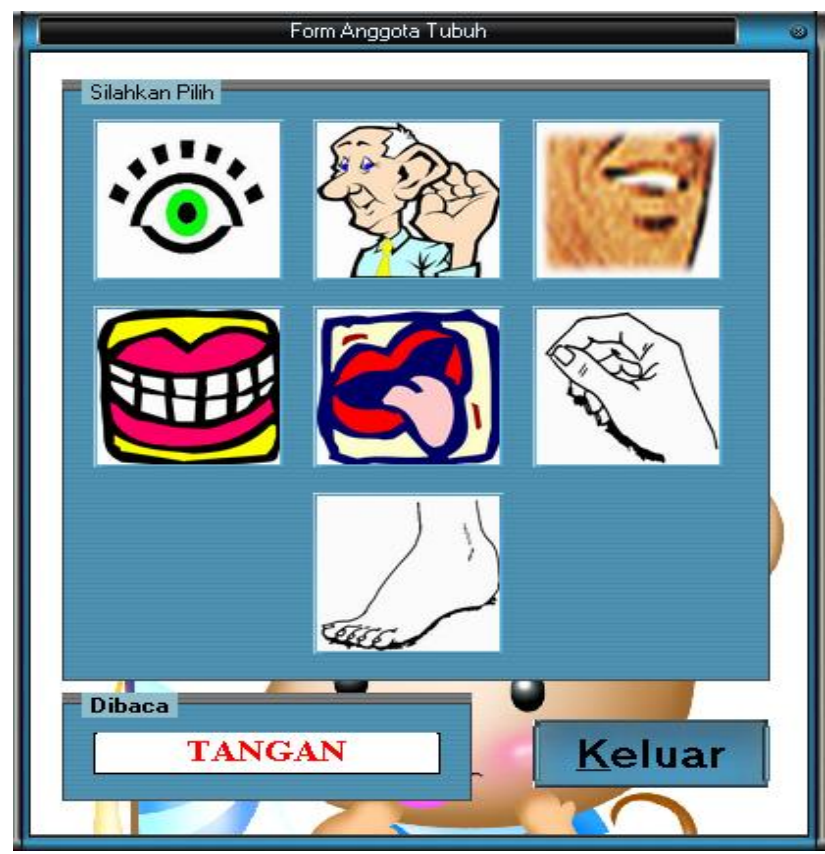

Gambar 10. Form Anggota Tubuh 
8. Tampilan Form Buah

Tampilan form buah ini memperkenalkan nama-nama buah bagi anak-anak TK.

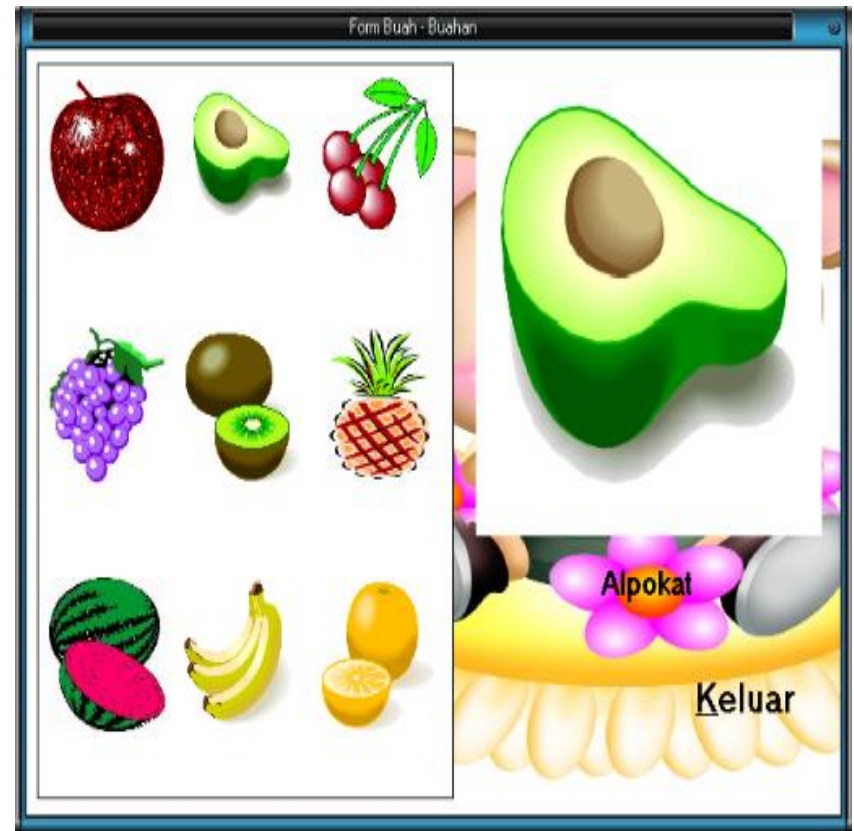

Gambar 11. Form Buah

9. Tampilan Transportasi

Tampilan transportasi ini memperkenalkan transportasi yang ada didalam aplikasi.

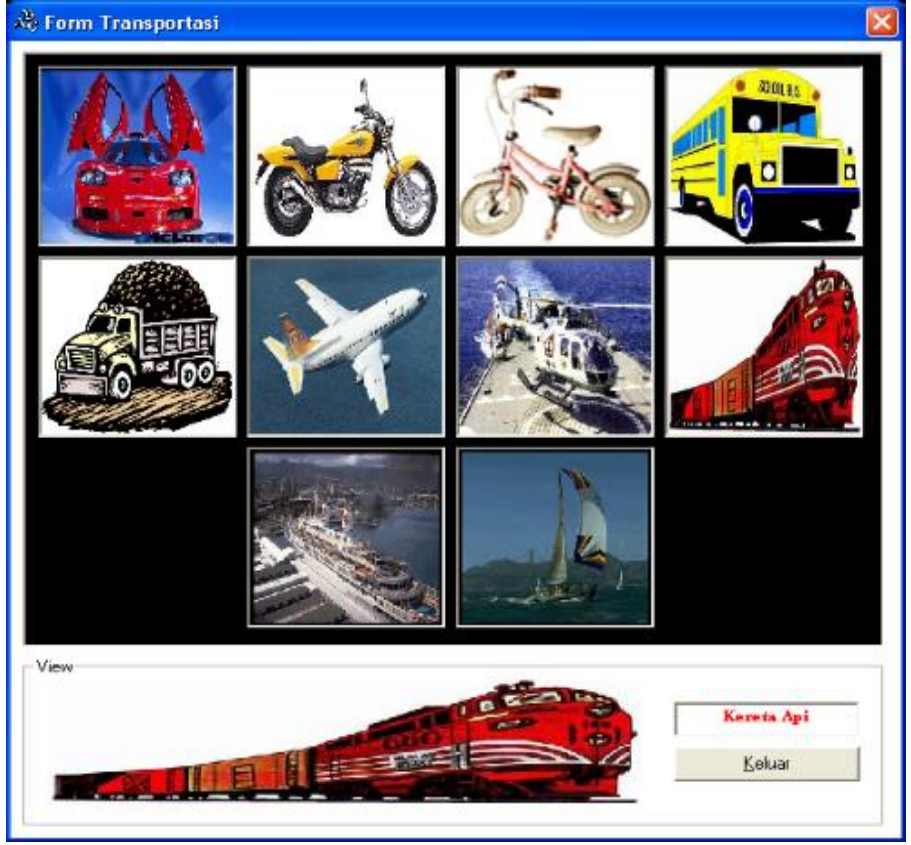

Gambar 12. Form Transportasi 
10. Tampilan Menulis

Tampilan menulis ini merupakan tampilan anak-anak belajar menulis dengan kearutan hampir $80 \%$ maka akan muncul huruf yang sesuai dengan yang ditulis.

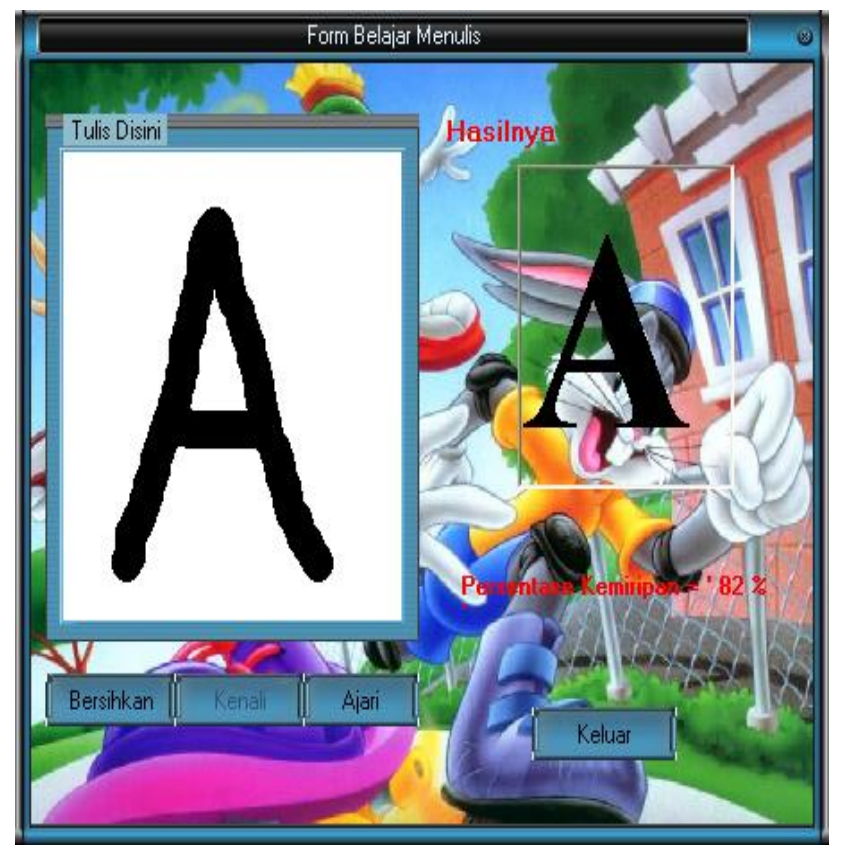

Gambar 13. Form Transportasi

11. Tampilan Game

Tampilan game ini merupakan game untuk mencocokkan gambar agar gambar yang cocok akan terbuka dengan pasangan gambar tersebut.

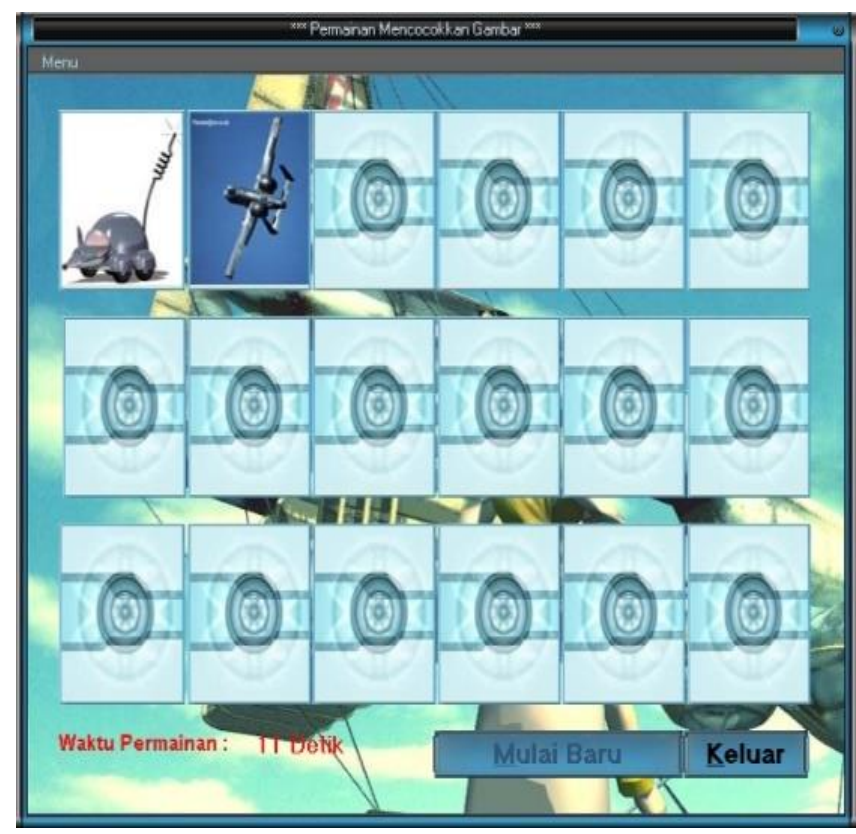

Gambar 14. Form Game 
12. Tampilan Puzzle

Tampilan Puzzle ini merupakan mengasah otak anak untuk menyusun gambar sehingga menjadi sebuah gambar yang utuh.

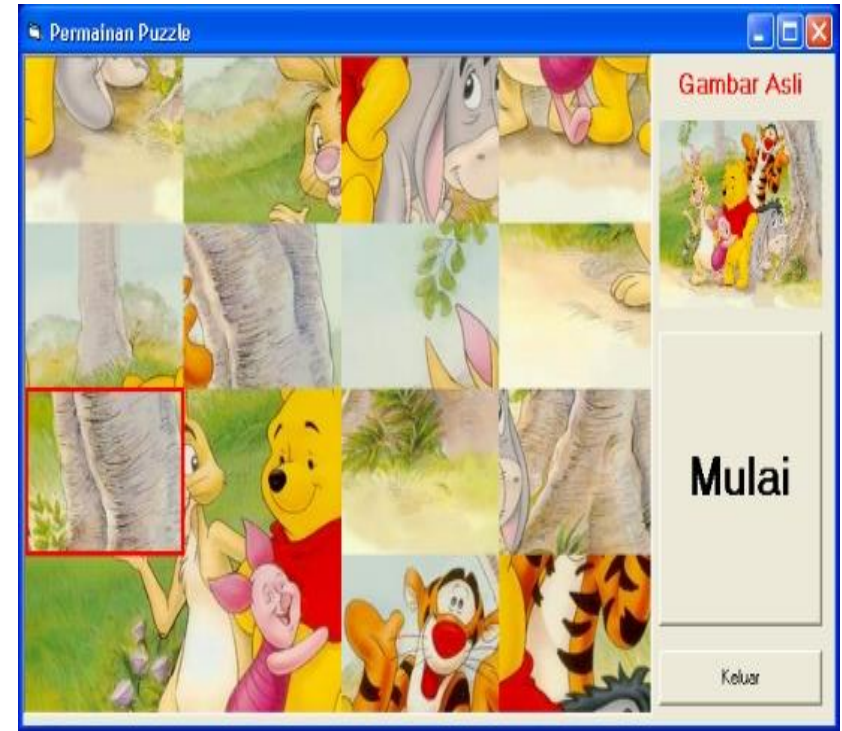

Gambar 15. Form puzzle

13. Tampilan Mewarnai

Tampilan mewarnai ini merupakan tampilan memberikan warna sesuai warna yang tersedia di form.

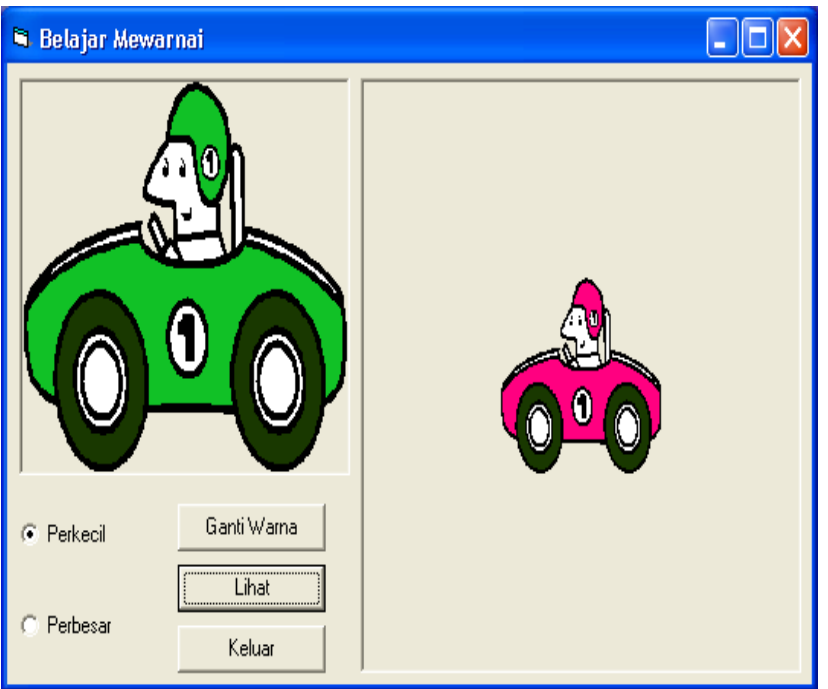

Gambar 16. Form Mewarnai

\section{KESIMPULAN}

Aplikasi multimedia pembelajaran interaktif pada anak tk ini sebagai berikut :
1. Sebagai alat bantu untuk melafalkan angka, huruf, gambar, anggota tubuh, warna, merangsang otak anak untuk menyusun gambar serta permainan yang mencocokkan dengan output suara. 
2. Dapat memacu daya pikir dan kreatifitas anak dalam bidang pendidikan, dan juga dapat memacu perkembangan anak itu sendiri dengan bantuan Teknologi dalam proses pembelajaran disekolah.

\section{SARAN}

Aplikasi ini dapat dikembangkan untuk aplikasi mobile dan juga aplikasi dengan vitur 3 dimensi.

\section{DAFTAR PUSTAKA}

[1] Ade Riyanti., Rizal Isnanto., Kurniawan Teguh martono., 2015 " Aplikasi Multimedia sebagai Media Pembelajaran Ilmu Pengetahuan Sosial Materi Budaya di Indonesia menggunakan Unity Engine untuk Sekolah Dasar., Jurna Teknologi dan Sistem Komputer, Vol.3, No.4 hal 471-
480

[2] Juhaeri. Pengertian dan Perancangan Aplikasi Multimedia. Jakarta: PT Elex Media Komputindo. 2002.

[3] Zulkarnain Effendi., Murinto. 2015, “APLIKASI MULTIMEDIA SEBAGAI MEDIA INFORMASI PADA PENGENALAN MONUMEN YOGYA KEMBALI YOGYAKARTA ” Jurnal Sarjana Teknik Informatika e-ISSN: 2338-5197 Volume 2 Nomor 1, hal 1039-1050

[4] Andriana, Joni, and Bambang Eka Purnama. Pembuatan Animasi Film Kartun Dengan Komputer Multimedia. Speed-Indonesian Journal on Computer Science 7(2). 2010.

[5] Komputer, Wahana. Buku Latihan: Teknik Mengolah Foto Digital Dengan Adobe Photoshop Cs3. Elex Media Komputindo. 2007 